$\xi=$

\title{
Nurses' KAP related to research conduct and utilization: EBNP "are we ready yet.
}

\author{
Dr. Amel Abouelfettoh ${ }^{1,2}$,Dr. Elham Al Ateeq ${ }^{3}$ \\ ${ }^{1}$ College of Nursing, King Saud bin Abdul-Aziz University for Health Sciences, KSA \\ ${ }^{2}$ Faculty of Nursing, Cairo University, Egypt \\ ${ }^{3}$ Imam Abdurrahman Bin Faisal University, College of Nursing, KSA \\ *Corresponding author E-mail: abouelfettoha@ngha.med.sa
}

\begin{abstract}
Background: Nurses make a positive difference every day and continue to shape the future of healthcare through planning, implementation and dissemination of quality research studies. The practice of evidence-based nursing is determined by the nurse's clinical experience as well as clinically relevant research knowledge, willingness to apply research to practice, and the skills to do so. No previous studies had been conducted to assess the conduct and utilization of nursing research and EBP in the Eastern province of Saudi Arabia.

Objective: Assess current nurses' research knowledge, attitude, and practice related to research conduct and utilization and to determine individual, organizational and contextual factors that predicts nurses' ability to conduct and utilize research findings into practice.

Methods: Descriptive correlational cross-sectional design utilized to study a convenient sample of 719 nurses working at different health care sectors in the Eastern Region of KSA. [33] Items Research KAP Survey measured nurses' KAP related to research $\odot$ (KAP), a. three level Likert Scale (ranging from one to 3). Score less than 1.66 is "low, 1.67 to 2.33 is "moderate" and 2.34 to 3.0 is "high".

Results: A response rate of $89.9 \%$ was obtained. Nurses were mostly females, aged between 30 to 40 years. Nurses' knowledge and attitude levels were moderate $(1.78,1.88$ respectively), however the practice was low (1.31). Individual factors explained $77.4 \%$ (R2 $=.774, \mathrm{~F}(5)=458, \mathrm{p}<.001)$, contextual factors explained $8 \%(\mathrm{R} 2=.089, \mathrm{~F}(4)=15.2, \mathrm{p}<.001)$, and organizational factors explained $77.4 \%$ of the nurses ability to practice evidence based $(\mathrm{R} 2=.774, \mathrm{~F}(5)=458, \mathrm{p}<.001)$.

Conclusion: The study findings provide feedback to strengthen nursing research competencies at the regional level and to the Development of nursing research-related policies, guidelines, and educational programs for evidence based nursing practice.
\end{abstract}

Keywords: Evidence- Based; Nursing Practice; Saudi Arabia.

\section{Introduction}

Evidence Based Nursing Practice (EBNP) becomes the new clinical standard in the nursing profession. The practice of evidencebased nursing is determined by the nurse's clinical experience as well as clinically relevant research knowledge, willingness to apply research to practice, and the skills to do so. Based on research findings, health care agencies and professional organizations are establishing new practice guidelines that maintain high quality safe patient care (Deegan, 2013; Asuquo et al., 2013) Therefore, nurses should be able to effectively integrate the results of published research into nursing practice, as well as to expand the knowledge base by conducting research as a regular part of clinical practice. The Institute of Medicine (IOM) aiming that by 2020, ninety percent of all health care decisions made evidence based (IOM, 2013), previous research have reported that the use of research evidence is often not reflected in the delivery of nursing care despite the benefits of adopting research-based practices, and the increased availability of research to health professionals (Wangensteen et al., 2011). As a result, patients often do not receive optimal or effective nursing care.

Fineout-Overholt and associates (2010) indicated that efforts to change clinical practice can be hindered by various factors including individual and organizational barriers. Additionally, variation of research conduct and utilization among nurses has been ex- plained in previous research studies by individual, organizational, and recently contextual factors (Squires, et al., 2011). Traditionally, the factors examined in nursing had been explained to be determinants of research use that are characterized as individual or personal factors, such as; age, attitude toward research use (Chien, et al., 2013), clinical setting factors and prior research knowledge (Eizenberg, 2011; Sanjari, et al., 2015) as well as the employment status and years of experience in the nursing profession (Wallin, et al., 2012). Pryse, McDaniel, and Schafer (2014) explained that organizational factors also have an influence on the nurses' research conduct and utilization Those factors include: complexity and size of the health care facility, presence of a research champion, traditionalism, access to, and amount of resources, as well as organizational support and professional autonomy (Abad-Corpa et al., 2013).

More attention is given to contextual factors in promoting research use in healthcare settings. Contextual factors are factors related to the setting in which proposed change is being implemented and it comprised of three dimensions: culture (beliefs and values), leadership (clear roles, teamwork, and effective organizational structure, and staff involvement in decision making. Research findings have shown that organizational structures, roles and policies, favorable organizational climate towards research use, material support to attend conferences, time to read research, educational activities had significant association with research use among nurses (Aarons, et al.,, 2015; Melnyk, et al., 2010; Stokke, et al., 2014). 
For nurses to conduct and use research in clinical practice, it is very crucial to systematically account for the factors that influence their use and conduct of research within the organizational setting. To formulate appropriate strategies to account for those factors and to foster the development of research in daily nursing practice at a regional level, the current study aims: to assess current nurses' research knowledge, attitude, and practice related to research conduct and utilization, and to determine the individual, contextual and organizational factors that predict nurses' research knowledge, attitude, and practice related to research conduct and utilization.

\section{Materials and methods}

The study was approved by the Research Scientific Committee at King Abdullah International Medical Research Center; MNGHA and IRB approval was obtained. Data was collected during the period from January 2016 to May 2017. Descriptive crosssectional correlational design was used for the purpose of the study. Based on a sample size calculation using previous research study (Eller, et al., 2003), a convenient sample of 700 nurses from different health care sectors (semi-governmental, Governmental and private) in the eastern province of KSA were approached by a research coordinator to participate in the study. Nurses' research knowledge, attitude, and practice were measured by Nurses' Research KAP Survey@ (KAP). The 33 item survey includes three separate but related scales that measures knowledge, attitude, and ability to performer activities related to research conduct and utilization (Burke, et al., 1999; Van-Mullem et al., 1999). The development of the survey items was based on the research utilization process steps described in the Iowa Model for Evidence-Based Practice (Titler, et al., 1994). The survey describe the research activities that are categorized under five factors: 1) identifying clinical problem, 2) establishing current best practice, 3) implementing research into practice, 4) administering research implementation, and 5) conducting and communicating research. Each item describes a research activity, for each activity listed on the survey the participants will indicate their level of knowledge, willingness to engage (attitude), and ability to perform (practice) the specific activity by rating their responses from 1 to 3, with 1 indicates "low", 2 indicates "moderate, and 3 indicates "high". Summary score for each subscale was calculated by totaling responses for each item and divided by 33 (the total number of survey items). Scores from 1.0 to 1.66 considered "low, scores from 1.67 to 2.33 considered "moderate" and scores from 2.34 to 3.0 considered "high". The content, and construct validity, and reliability of the survey subscales have been established in previous research (Burke, et al., 1999). Demographic data sheet was developed for the purpose of the study and it includes questions related to individual factors; age, education, years of experience, previous research activities, organizational support factors; research workshops, research activities, participation in research activities, and contextual factors; availability of research center, library and access to data base, an open ended question was asked about how subjects perceive their work environment as challenging and/or facilitating their involvement in research activities and use of research findings in clinical practice. Data was entered into the Statistical Package for Social Sciences (SPSS) version18.0. Descriptive analysis was performed to describe sample characteristics and study variables. Regression analysis was used to explain the contribution of the individual, contextual and organizational to the nurses' ability to implement evidence based practice after dummy coding of the categorical variables.

\section{Results}

In the two biggest cities in the Eastern Region of Saudi Arabia, out of 800 approached nurses, 719 participated, giving a response rate of $89.9 \%$, out of which $51.3 \%$ from Al Ahsa and $48.7 \%$ from Al Damam city, 153 participants from two NGHA hospitals, 532 participants from four $\mathrm{MOH}$ hospitals and 34 participants from two private hospitals. Table1 shows distribution of the subjects' demographics. Nurses were mostly females, working at different units, aged between 30 to 40 years, Filipino, with more than 5 years of professional experience but less than five years working in their current hospital.

Table 1: Distribution of Participants ' Demographic Characteristics

\begin{tabular}{|c|c|c|c|}
\hline Characteristics & Categories & Frequency* & Percentage \\
\hline \multirow{3}{*}{ Age group } & Under 30 & 253 & $35.3 \%$ \\
\hline & $30-40$ & 318 & $44.7 \%$ \\
\hline & More than 40 & 144 & $20 \%$ \\
\hline \multirow{3}{*}{ Gender } & Female & 632 & $87.9 \%$ \\
\hline & Male & 87 & $12.1 \%$ \\
\hline & Saudi & 223 & $30.9 \%$ \\
\hline \multirow{3}{*}{ Nationality } & Filipino & 268 & $37.2 \%$ \\
\hline & Indian & 122 & $17.0 \%$ \\
\hline & Other & 107 & $14.9 \%$ \\
\hline \multirow{3}{*}{ Level of Education } & Diploma & 395 & $54.9 \%$ \\
\hline & Baccalaureate & 308 & $42.8 \%$ \\
\hline & Postgraduates & 16 & $2.3 \%$ \\
\hline \multirow{4}{*}{ Years of Experience } & $<3$ years & 133 & $19.1 \%$ \\
\hline & $3-5$ years & 200 & $28.7 \%$ \\
\hline & $6-9$ years & 123 & $17.6 \%$ \\
\hline & $\begin{array}{l}10 \text { years and } \\
\text { up }\end{array}$ & 237 & $34.1 \%$ \\
\hline \multirow{4}{*}{$\begin{array}{l}\text { Years working in the } \\
\text { hospital }\end{array}$} & $<3$ years & 268 & $37.2 \%$ \\
\hline & $3-5$ years & 203 & $28.2 \%$ \\
\hline & $6-9$ Years & 114 & $15.9 \%$ \\
\hline & $\begin{array}{l}10 \text { years and } \\
\text { up }\end{array}$ & 112 & $15.6 \%$ \\
\hline \multirow{3}{*}{ Specialty/Unit } & $\begin{array}{l}\text { Medical- } \\
\text { Surgical }\end{array}$ & 298 & $49.3 \%$ \\
\hline & Maternal Child & 179 & $29.6 \%$ \\
\hline & Critical Care & 128 & $21.2 \%$ \\
\hline \multirow{3}{*}{ Hours / shift } & 12 hours shift & 111 & 16.7 \\
\hline & 8 hours shift & 388 & 58.5 \\
\hline & Others & 164 & 24.7 \\
\hline
\end{tabular}

*Note: The total number of respondents in the study was 719. However, the 'total' categories do vary since some respondents left some of the demographic questions blank.

About half of the participants $(49.1 \%)$ had research course in their formal nursing education but without a component foundations of EBP, most of them (69.5\%) never attended research meetings or workshops during their professional life, and did not participate in any research studies $(68.8 \%)$, only $33 \%$ of those participated in research were the principal or co- investigators, however most of them $(60.8 \%)$ were only participated in data collection (Table 2 ).

Table 2: Participants' Research Experience

\begin{tabular}{llll}
\hline Research Experience & Responses & No. & Percent \\
\hline Research course during nursing edu- & No & 336 & 50.9 \\
cation & Yes & 324 & 49.1 \\
Attend research meetings Or work- & No & 459 & 69.5 \\
shops? & Yes & 201 & 30.5 \\
Is mandatory to attend research work- & No & 449 & 68.1 \\
shop & Yes & 210 & 31.9 \\
Previously participated & No & 454 & 68.8 \\
In any research study? & Yes & 206 & 31.2 \\
& PI & 30 & 14.5 \\
& Co-I & 41 & 19.9 \\
If yes, what was your role? & Data collection & 125 & 60.8 \\
& Committee & 10 & 4.8 \\
How often do you & member & 89 & 13.5 \\
Read a research article? & Never & 532 & 80.6 \\
& Sometimes & 39 & 5.9 \\
\hline
\end{tabular}


Table 3: Organizational /Contextual Factors

\begin{tabular}{llll}
\hline & Response & Number & Percent \\
\hline Is there a library & No/I do not Know & $11 / 30$ & $1.7 / 4.6$ \\
In the hospital? & Yes & 613 & 93.7 \\
If yes, how often & Never & 241 & 36.9 \\
Do you use it? & Sometimes & 399 & 61.0 \\
Do you access to internet & Always & 14 & 2.1 \\
and data base & No/ I do not Know & 353 & 54.1 \\
Do you read research arti- & Yes & 299 & 45.9 \\
cles & Never & 89 & 13.5 \\
& Sometimes & 532 & 80 \\
Research Center & Always & 39 & 6.9 \\
& No/ I do not Know & 447 & 71.7 \\
\hline
\end{tabular}

Most of the hospitals have a library (93.7\%), but very few of the participants use it $(2.1 \%)$. Have no research center or access to research data base $(71.7,54.1)$ respectively. Most of the participants perceive their work environment as encouraging for conduct and use of research findings to change current nursing practice. Table 4 shows that Nurses' knowledge and attitude levels were moderate (1.78, 1.88 respectively), however the practice level was low (1.31). In terms of subscales scores, the participants' knowledge of identifying clinical problems (factor 1) was the highest among the nurses in knowledge, attitude as well as practice the other four factors were low. * Scores from 1.0 to 1.66 considered "low, scores from 1.67 to 2.33 considered "moderate" and scores from 2.34 to 3.0 considered "high.

Correlation and multiple regression analyses were conducted to examine the relationship between the nurses EBP score and various potential predictors (individual, contextual and organizational). Table 5 summarizes the descriptive statistics and regression analysis results for nurses' individual factors (Knowledge, Attitude, Age, Level of education, and years of experience). The results of the regression indicated the individual factors /predictors explained $77.4 \%$ of the nurses ability to practice evidence based $\left(\mathrm{R}^{2}=.774, \mathrm{~F}(5)=458, \mathrm{p}<.001\right)$. It was found that EB knowledge significantly predicted the nurses ability to practice $\mathrm{EB}(\beta=.58$, $\mathrm{p}<.001)$, as did the nurses' attitude $(\beta=-.35, \mathrm{p}<.001)$, however, nurses age, education or years of experience did not.

Table4: KAP Survey Descriptive Statistics ( $\mathrm{N}=719)$

\begin{tabular}{|c|c|c|c|c|c|c|c|c|}
\hline & \multicolumn{2}{|c|}{ Knowledge Score* } & \multicolumn{2}{|c|}{ Attitude Score* } & \multicolumn{2}{|c|}{ Practice Score* } & \multicolumn{2}{|c|}{ Total KAP Score* } \\
\hline & Mean & SD & Mean & SD & Mean & SD & $\mathrm{M}$ & SD \\
\hline Total Scale & 1.79 & 0.67 & 1.88 & 0.67 & 1.31 & 0.68 & 1.66 & 0.67 \\
\hline Identifying clinical Problems & 2.04 & 0.73 & 2.38 & 0.69 & 2.01 & 0.71 & 1.66 & 0.71 \\
\hline Implementing Research into practice & 1.37 & 0.69 & 1.96 & 0.67 & 1.11 & 0.72 & 1.48 & 0.69 \\
\hline Administering research Implementation & 1.61 & 0.65 & 1.88 & 0.68 & 1.12 & 0.68 & 1.54 & 0.67 \\
\hline Conducting and communicating Research & 1.61 & 0.65 & 1.88 & 0.68 & 1.30 & 0.69 & 1.58 & 0.67 \\
\hline Total Scale $\mathrm{M} \pm \mathrm{SD}$ & 1.68 & 0.67 & 1.95 & 0.67 & 1.31 & 0.68 & 1.64 & 0.67 \\
\hline
\end{tabular}

Table5: Summary Statistics, Correlations and Results from the Regression Analysis

\begin{tabular}{|c|c|c|c|c|c|}
\hline \multirow{3}{*}{$\begin{array}{l}\text { Variable } \\
\text { Practice Score }\end{array}$} & \multicolumn{2}{|c|}{ Descriptive } & \multirow{2}{*}{$\begin{array}{l}\text { Correlation } \\
\text { with practice score }\end{array}$} & \multicolumn{2}{|c|}{ Multiple regression } \\
\hline & Mean & & & $\mathrm{b} \beta^{*}$ & \\
\hline & 1.82 & 0.51 & & & \\
\hline Knowledge Score & 1.80 & $0.48 \%$ & 0.58 & 0.61 & $0.585^{\text {*** }}$ \\
\hline $\begin{array}{l}\text { Education } \\
\text { (BSN and higher) }\end{array}$ & 324 & $45.1 \%$ & 0.10 & 0.03 & 0.036 \\
\hline Experience $>5$ years & 360 & $50.1 \%$ & 0.11 & 0.12 & $0.11^{* *}$ \\
\hline
\end{tabular}

$* \mathrm{P}<.05 * * \mathrm{p}<.01 * * * \mathrm{p}<.001$

Table 6: Summary Statistics from Regression Analysis for Contextual Factors

\begin{tabular}{|c|c|c|c|c|c|}
\hline Variable & \multicolumn{2}{|c|}{ Descriptive } & Correlation coefficient & \multicolumn{2}{|c|}{ Multiple regression weights } \\
\hline Practice Score Mean, SD & 1.82 & 0.51 & & $\mathrm{~b}$ & $\beta^{*}$ \\
\hline Long Shifts (12 hours) & 111 & $15.4 \%$ & -0.17 & -0.258 & $-0.17 * * *$ \\
\hline Research course during nursing education & 381 & $53 \%$ & 0.07 & 0.05 & 0.05 \\
\hline Attend research meetings or workshops? & 459 & 63.8 & 0.21 & 0.16 & 0.15 \\
\hline $\begin{array}{l}\text { Is mandatory to attend } \\
\text { research workshop/course }\end{array}$ & 270 & 37.6 & 0.09 & 0.01 & 0.009 \\
\hline Previously participated in any research study? & 206 & 28.7 & 0.30 & 0.26 & $0.24 * * *$ \\
\hline
\end{tabular}

$* \mathrm{P}<.05 * * \mathrm{p}<.01 * * * \mathrm{p}<.001$

Table 7: Summary Statistics from Regression Analysis for Organizational Factors

\begin{tabular}{lllll}
\hline Variable & Descriptive & Correlation coefficient & Multiple regression weights & b \\
\hline Practice Score Mean, SD & 1.82 & 0.51 & & $\beta^{*}$ \\
Is there a library in the hospital? N,\% & 613 & $85.3 \%$ & 0.25 & 0.29 \\
Access to internet and data base N, \% & 299 & $41.6 \%$ & 0.38 & $0.19 *$ \\
Research Center N, \% & 176 & $24.5 \%$ & 0.04 & $22 *$ \\
\hline
\end{tabular}

$* \mathrm{P}<.05 * * \mathrm{p}<.01 * * * \mathrm{p}<.001$.

Results of the regression analysis indicated that contextual factors /predictors explained only $8 \%$ of the nurses ability to practice evidence based $\left(\mathrm{R}^{2}=.089, \mathrm{~F}(4)=15.2, \mathrm{p}<.001\right)$, long shift $(12$ hours) previous participation in a research project were significantly related to the nurses ability to perform EBP $(\beta=.-.17$, $\mathrm{p}<$ $.001, \beta=.24, \mathrm{p}<.001)$ respectively.

The results of the regression indicated that organizational factors explained only $4 \%$ of the nurses ability to practice evidence based $\left(\mathrm{R}^{2}=.040, \mathrm{~F}(2.4)=9.4, \mathrm{p}<.001\right)$, presence of a library with access to database was significantly related to the nurses ability to perform $\operatorname{EBP}(\beta=.26, \mathrm{p}<.001)$.

\section{Discussion}

No previous studies had been conducted to assess the conduct and utilization of nursing research and EBP in the Eastern province of Saudi Arabia. In order to design interventions that increase research use in nursing, it is necessary to address what influences research use. The results of the current study provide a baseline for developing a strategic plan aiming to improve evidence based nursing practice and will guide the nursing research agenda in the Eastern Province of Saudi Arabia. 
The results showed that the nurses' attitude scored the highest compared to the knowledge and practices scores, moreover, nurses' attitude toward EBP explained about $30 \%$ of the nurses' ability to perform EBP skills. The importance of a good understanding of the attitude, awareness of health professionals about implementation of evidence-based practice was emphasized (Maaskant, et al., 2013). Positive attitudes toward EPB will definitely lead to better understanding and implementation of new research evidences into practice. Additionally, nurses' attitude is positively correlated with their ability to implement new research evidences into practice which was scored low in the current study (Adejumo \& Guobadia, 2013). Nurses' lack of knowledge about EBP needs to be addressed. Participants' knowledge level was ranging from low to moderate and it explains about $60 \%$ of the nurses EBP skills. Participants' level of nursing education contributed to the results because most of the participants were only educated on the level of nursing diploma or associate degree which is perceived to be a major disadvantage because of the lack of training in research utilization (Staffileno \& Carlson, 2010). Therefore barriers to EBP may be reduced or eliminated with education (Grant, et al., 2012). The long-term effect of education on nurses' beliefs/attitudes toward and use of EBP should be fostered and built into the organization's culture and competencies (Wilson, et al., 2013).

Contextual and Organizational factors explained about $8 \%$ and $4 \%$ of the nurses' ability to implement EBP respectively. Participants perceived that their work environment is encouraging them to conduct research and utilize research findings to change practice. Pryse and associates (2014) indicated that evidence based practice may be moving away from the individual to organizational factors. It is not suggested that the staff nurse's contribution to EBP is minimal, but instead that the success of the staff nurse to engage in EBP relies on a supportive work environment and effective nursing leadership. It is very important to provide the nurses with the required resources needed to find the updated research evidences from research results. In spite of $93 \%$ of the participants have an access to a library in their hospitals, and $45 \%$ have an access to a research data base, only about $6 \%$ read research articles. Nurses" attitude to reading research articles was emphasized by Adejumo, and Guobadia (2013). Nurses reported that the lack of time to read research findings was the most important barrier to implement EBP activities and even if they have time to read, they had difficulty understanding statistics (Maaskant, et al, 2013).

Recent research recommended that hospital management should improve Information and Communication Technology (ICT) infrastructure to facilitate access to better Evidence Based Information (Monde, et al., 2017). In the current study, Nurses usually do not know how to use electronic databases. The majority of nurses did not search databases to find practice information and those nurses who did search felt they lacked well-defined search skills. This will have implications for identifying and testing strategies to influence EBP activities through development of nursing leadership skills for EBP and creating a more EBP friendly work environment and providing nurses with time and resources to implement evidence based nursing practices (Bahadori, et al., 2016). Finally, nurses would benefit from additional research education and support within their organizations to ensure that patients and families are receiving care based on sound, high quality research evidence. A variety of ways were suggested to help educate nurses about research utilization and implementation of EBP, for example: hiring a clinical nurse specialists or master's-prepared unit educators, a doctoral prepared nurse researcher might create classes to teach nurses how to read the literature and understand statistical findings, hospitals also might partner with nursing college to offer such classes, and hospital-based librarians could visit the nursing units to provide in-service training in how to search the literature. Additionally, collaboration between academics and nursing services is suggested to conduct collaborative research studies with emphasis on research actually used in practice is (Rycroft-Malone, et al., 2011). In conclusion, the study findings provide feedback to strengthen nursing research competencies at the regional level and to the Development of nursing research- related policies, guidelines, and educational programs for evidence based nursing practice.

\section{Recommendations for future research}

1) Development of standard measures of research use.

2) Strong well-designed studies to assess nurses' use of research and its impact on patient outcomes.

3) Identify strategies to increase the research knowledge and skills of nurses.

4) Compare the evidence-based practice and research utilization of nurses with other health care professional groups.

\section{References}

[1] Abad-Corpa, E, Delgado-Hito, P, Cabrero-García, J, MeseguerLiza, C, Zárate-Riscal, CL, Carrillo-Alcaraz, A \& CaravacaHernández, A. (2013). Implementing evidence in an oncohaematology nursing unit: A process of change using participatory action research. International Journal of Evidence Based Healthcare, 11: 46-55.

[2] Adejumo, PO. \& Guobadia PO. (2013). Nurses' attitude to reading research articles and their perception of research utilization in clinical practice in a Nigerian city. Journal of Medicine and Biomedical Research, 12 (1): 46-56.

[3] Aarons, G A, Ehrhart, M G, Farahnak, L R, \& Hurlburt, M S. (2015). Leadership and organizational change for implementation (LOCI): A randomized mixed method pilot study of a leadership and organization development intervention for evidence-based practice implementation. Implementation Science, 10-11.

[4] Asuquo, EF, Etowa J, John M, Ndiok, A, Sampson-Akpan P \& Edet O. (2013). Assessing nurses' capacity for health research and policy engagement in Nigeria. Journal of Applied Medical Science, 2(2):35-51.

[5] Bahadori, M, Raadabadi, M, Ravangard, R \& Mahaki, B. (2016). The barriers to the application of the research findings from the nurses' perspective: A case study in a teaching hospital. Journal of Education and Health Promotion, 5, 14. 10.4103/22779531.184553. https://doi.org/10.4103/2277-9531.184553.

[6] Burke, LJ, Farrell, MP, Brukwitzki, G, \&Van Mullem, C. (1999). Nurses' Knowledge, Attitude, and Practices of Research Survey. Nursing Research Center, Aurora Health Care-Metro Region. Milwaukee WI, retrieved from https://www.aurorahealthcare.org/

[7] Chien, WT, Bai, Q, Wong, WK, Wang, H \& Lu, X. (2013). Nurses' perceived barriers to and facilitators of research utilization in mainland china: A cross-sectional survey. Open Nursing Journal, 7, 96106. https://doi.org/10.2174/1874434601307010096.

[8] Deegan, J (2013). A view from the outside: Nurses' clinical decision-making in the twenty first century. Australian Journal of Advanced Nursing, 30(4): 12-18

[9] Eizenberg, MM. (2011). Implementation of evidence-based nursing practice: Nurses' personal and professional factors. Journal of Advanced Nursing, 67:33-42. https://doi.org/10.1111/j.13652648.2010.05488.x.

[10] Eller, LS, Kleber, E, \& Wang, SL. (2003). Research knowledge, attitudes and practices of health professionals. Nursing Outlook, 51(4): 165-170. https://doi.org/10.1016/S0029-6554(03)00112-X.

[11] Estabrooks, CA, Midodzi, WK, Cummings, GC, Wallin, L, \& Adewale, A. (2007). Predicting research use in nursing organizations: A multilevel analysis. Nursing Research. 56 (Suppl): 7-23. https://doi.org/10.1097/01.NNR.0000280647.18806.98.

[12] Fineout-Overholt, E, Williamson, K, Kent, B \& Hutchinson, A. (2010). Teaching EBP: strategies for achieving sustainable organizational change toward evidence based practice. Worldviews on Evidence-based Practice, 1, 51-53. https://doi.org/10.1111/j.17416787.2010.00185.x.

[13] Grant, HS, Stuhlmacher, A \& Bonte-Eley, S. (2012). Overcoming barriers to research utilization and evidence-based practice among staff nurses. Journal of Nurses in Staff Development, 28(4): 163165. https://doi.org/10.1097/NND.0b013e31825dfaff.

[14] Institute of Medicine [IOM] (2013). Crossing the quality chasm: The IOM health care quality initiative. Retrieved on September 10 , 2016 from: The future of nursing: Leading change, advancing health [prepared by Robert Wood Johnson Foundation Committee Initiative on the Future of Nursing]. Washington, DC: National $\begin{array}{lll}\text { Academies } & \text { Press. } & \text { Retrieved }\end{array}$ http://www.iom.edu/Global/News\%20Announcements/Crossing- 
the-Quality-Chasm-The-IOM-Health-Care-QualityInitiative.aspx https://doi.org/10.1016/j.pedn.2012.05.002.

[15] Maaskant, JM, Knops, AM, Ubbink. DT \& Vermeulen, H. (2013). Evidence-Based Practice: A Survey among Pediatric Nurses and Pediatricians. Journal of Pediatric Nursing, 28(2), 150-157. https://doi.org/10.1016/j.outlook.2010.06.002.

[16] Melnyk, BM, Fineout-Overholt, E, Giggleman, M, \& Cruz, R. (2010). Correlates among cognitive beliefs, EBP implementation, organizational culture, and cohesion and job satisfaction in evidence-based practice mentors from a community hospital system. Nursing Outlook, 58(6):301-308.

[17] Monde, MW, Akakandelwa, A \& Kanyengo, CW. (2017). Nurses and Use of Research Information in Clinical Practice: a Case Study of the University Teaching Hospital in Zambia. Library Philosophy and Practice. (E-journal). 1560. Available at: http://digitalcommons.unl.edu/libphilprac/1560 https://doi.org/10.1111/wvn.12045.

[18] Pryse. Y1, McDaniel. A \& Schafer, J. (2014). Psychometric analysis of two new scales: the evidence-based practice nursing leadership and work environment scales. Worldviews Evidence Based Nursing, 11(4), 240-247.

[19] Rycroft-Malone, J, Wilkinson, JE, Burton, CR, Andrews, G, Ariss, S \& Baker, R, et al. (2011). Implementing health research through academic and clinical partnerships: a realistic evaluation of the Collaborations for Leadership in Applied Health Research and Care (CLAHRC). Implementation Science, $19, \quad 6: 74$. https://doi.org/10.4103/1735-9066.164501.

[20] Sanjari, M, Baradaran, HR, Aalaa, M \& Mehrdad, N. (2015). Barriers and facilitators of nursing research utilization in Iran: A systematic review. Iran Journal of Nursing Midwifery Research. 20(5): 529-539.

[21] SPSS Inc. Released 2009. PASW Statistics for Windows, Version 18.0. Chicago: SPSS https://doi.org/10.1186/1748-5908-6-1.

[22] Squires, JE, Estabrooks, CA, Gustavsson, P \& Wallin, L. (2011) Individual determinants of research utilization by nurses: a systematic review update. Implementation science, 5: 6-1. https://doi.org/10.1111/j.1365-2834.2009.01048.x.

[23] Staffileno, BA \& Carlson, E. (2010). Providing direct care nurses research and evidence-based practice information: an essential component of nursing leadership. Journal of Nursing Management, 18(1): 84-89. https://doi.org/10.1186/1472-6955-13-8.

[24] Stokke, K, Olsen, NR, Espehaug, B \& Nortvedt, MW. (2014). Evidence based practice beliefs and implementation among nurses: A cross-sectional study. BMC Nursing, 13:8.

[25] Titler, MG, Kleiber, C, Steelman, V, Goode, C, Rakel, B, BarryWalker, J, Small, S \& Buckwalter, K. (1994). Infusing research into practice to promote quality care. Journal of Nursing Research, 43(5): 307-13. $\quad$ https://doi.org/10.1097/00005110-199912000$\underline{00008}$

[26] Van-Mullem, C, Burke, LJ, Dohmeyer, K, Farrell, M, Harvey, S, John, L, Kraly, C, Rowley, F, Sebern, M, Twite, K, \& Zapp, R. (1999). Strategic planning for research use in nursing practice. Journal of Nursing Administration, 29 (12): 38-45. https://doi.org/10.1186/1748-5908-7-19.

[27] Wallin. L, Gustavsson, P, Ehrenberg, A \& Rudman, A. (2012). a modest start, but a steady rise in research use: A longitudinal study of nurses during the first five years in professional life. Implementation Science, $\quad 7: 19$. $\quad$ https://doi.org/10.1111/j.13652702.2010.03629.x.

[28] Wangensteen, S, Johansson, IS, Björkström, ME \& Nordström, G. (2011). Research utilization and critical thinking among newly graduated nurses: predictors for research use. A quantitative crosssectional study. Journal of Clinical Nursing, 20: 2436-2447.

[29] Wilson. B, Kelly, L \& Reifsnider, E. (2013). Creative approaches to increasing hospital-based nursing research. Journal of Nursing Administration, $\quad 43(10)$ : $\quad 80-\quad 88$ https://doi.org/10.1097/NNA.0b013e31827f2043. 